\title{
Disaster Planning. A Major Accident Exercise
}

\author{
P. E. A. SAVAGE, * M.B., B.S., F.R.C.S.
}

British Medical fournal, 1970, 4, 168-171

\section{Introduction}

In the autumn of 1968 , I helped to revise the major accident procedure of a 296-bedded district general hospital near London, and a few months later the arrangements were tested in a simulated disaster arranged by the local constabulary. The exercise, code-named "Goldflight," took place on a cold wet Sunday morning in March 1969 and simulated a plane crash in a near-by town. Members of the casualty union realistically acted the parts of 40 casualties and there were also 23 dead bodies at the site of the crash, which had been constructed by a local film studio. The exercise was the first of its kind to be held in the area and had the full support of the firstaid organizations and all the emergency services, whose members, apart from the organizers, did not initially know that it was an exercise. The exercise was attended by over 70 police officers, 100 firemen with 15 appliances, and 15 ambulances and their crews.

To maintain secrecy the number of hospital staff involved in the planning stages was kept to a minimum but shortly before the exercise members of the medical staff on duty and key members of other hospital departments were briefed. Medical umpires were appointed to supervise the clinical care of "casualties" and also to make sure that no genuine casualty was overlooked. To safeguard patients in the hospital all wards were given a special internal telephone number so that they could obtain medical help during the exercise should the hospital switchboard be swamped with calls. The hospital cardiac arrest telephone number was specifically reserved for genuine calls.

\section{The Exercise}

\section{Telephonists}

The accident occurred at 10 a.m. and by 10.15 the hospital had been alerted by a telephone call from the police asking for the deputy [sic] medical officer. This call was promptly put through to the duty house-physician, who, under the impression that the call was from the Emergency Bed Bureau, said that he had no beds. This error was rapidly corrected. The orders to carry out major accident instructions having beeh given, the first duty of the telephonist was to call in another telephonist. Coincidentally, however, a second telephonist happened to be in the telephone room at the time, so there was no delay in calling the individuals on the telephonists' list. The acting matron was alerted at 10.16 , the main reception desk at 10.19 , and the acting hospital secretary at his home at 10.26. Matron's office informed the accident and emergency department at 10.19 , only three minutes before the first ambulance arrived.

The telephonists were then able to work through their list of individuals to be contacted, the only major problem being

* Senior Registrar, St. Mary's Hospital, London W.2. to locate the theatre superintendent or the deputy theatre superintendent. Eventually, after calls to the major accident officer at 10.52 and the sisters' home, it was finally discovered that the sister in charge of the theatres had been in the department all the time, but no one had explained what all the inquiries were about. By 11.25 the two telephonists were almost swamped with work, mainly in sending for members of the nursing staff, and had to call in a third telephonist. By this time they were also getting very thirsty.

\section{Major Accident Officer}

The major accident officer, having been alerted by the police at 10.15 , confirmed the validity of the message with the police operations room and directed the telephonists to carry out the major accident instructions. He then spoke to the site senior medical officer at 10.20, telling him of the accident and asking him to go to the site. The major accident officer arrived in the control centre at 10.23, where he was joined by members of the junior medical staff between 10.27 and 10.35. These doctors were briefed at 10.36 and sent to report to the orthopaedic registrar in the accident and emergency department. While the doctors were waiting to be briefed no one in the control centre knew that casualties had started to arrive.

Information from the scene of the accident was barely adequate. At 10.30 the police were able to say that there were 63 injured and that a police car was on its way to the hospital. This report was supplemented at 10.45 with the information that 10 seriously injured patients were being sent in. At 10.55 more details were available about the plane crash, and at 11.25 the news that a helicopter had crashed with no survivors was received. Messages were received by telephone via the ambulance headquarters and the police station, and also via the police radio car which arrived at the hospital at 10.45. It was impossible for the major accident officer to speak directly to the site senior medical officer. The first message from him was at 11.5 asking why the mobile medical team had arrived, as he had not yet sent for it. At 11.10 we heard that all casualties had been cleared, and at 11.30 the message "stand down" was received.

Communication within the hospital failed completely. We have already noted that, though the first ambulance arrived at the hospital at 10.22 , the control centre remained in ignorance of what was going on in the accident and emergency department until the major accident officer contacted the department at 10.56. The control centre was also completely ignorant of how many patients were being admitted, and when only one admission slip had been received by 11.15 it was discovered by telephoning the receiving ward that nine patients had already been admitted. Even when the major accident officer tried to telephone the accident and emergency department on the extension he had asked them to man, there was delay in getting any reply on a number of occasions. The bed state of the hospital was rapidly produced 
and made available to the major accident officer at 10.32 , while the Bed Bureau was able to let him have the bed states of hospitals in the group at 11.21. The fact that the hospital secretary and the matron were not in the same room as the major accident officer meant that the last had many messages to deal with which were properly the responsibility of these other officers.

\section{Accident and Emergency Department}

Despite the fact that the accident and emergency department was open for genuine casualties throughout the period of the exercise, it rapidly became obvious that, through no fault of the nursing and medical staff, this was the weakest section of the hospital.

Matron's office informed the sister in charge at 10.19 , three minutes before the first ambulance arrived, and so there was very little time to prepare the department. The accident and emergency department was eighth on the list of calls the switchboard had to make, and if the department had not been informed by matron's office ambulances would have started to arrive before they knew that there was a major accident. The shortage of portering staff during the initial four minutes made the reorganization of the department very difficult, and the fact that the department receptionist had to use a public telephone to call in non-resident nurses also meant that this clerical officer was not available for some time after casualties had started to arrive.

The documentation of casualties was very poor. Forty cases were admitted to the department, and examination of the casualty cards showed that in 11 cases names had not been recorded. Medical notes were also incomplete and often illegible. Of the seven casualty cards on which blood transfusions had been ordered four had no identifying name or number. The duty orthopaedic registrar was nominally in charge of the department, and he intended to sort the casualties as they entered into cases for immediate attention, major cases, and minor cases. Unfortunately, he was required to deal with genuine accident cases on several occasions. He also found it difficult to keep a senior nurse with him and impossible to obtain the assistance of a clerk. A contributory factor to this lack of liaison was that the nursing staff had to give treatment to 12 genuine casualties during the exercise.

\section{Mobile Medical Team}

The sortie of the mobile medical team from the hospital to the scene of the accident can only be described as a complete failure. On being alerted by matron's office the accident and emergency department nursing staff moved six heavy boxes of emergency equipment to the entrance of the department to await the ambulance supplied by the ambulance service. The first ambulance that arrived contained a supply of stretchers, and the team were told by the driver that this was not their vehicle. The equipment was loaded on to a second ambulance, which drove away without the medical team. Meanwhile the three nurses had changed into their protective clothing and were impatiently awaiting the casualty officer, who arrived at 10.40 . Contrary to his instructions and better judgment he was persuaded to join the nurses on another ambulance which they had commandeered, and they were driven to the site.

It was soon painfully obvious that the mobile medical team was ill-equipped in more ways than one to deal with the situation. Firstly, the clothing with which they were provided was inadequate. The white tracksuits were no protection against wind and rain; the heavy Wellington boots were uncomfortable to wear; and the miners' helmets and lamps with their battery boxes were heavy and cumbersome. There was also nothing to indicate that this was a medical team. As a result they soon had blistered heels, stiff necks, and were "frozen to the marrow." Secondly, the major accident equipment is very comprehensive; it consists of six large boxes, each one requiring at least two people to carry it. Thirdly, the instructions to the mobile medical team to "establish a casualty post ... . through which all casualties should so far as possible be channelled" was impracticable in this exercise.

\section{Site Senior Medical Officer}

The site senior medical officer was told of the accident at 10.20 and fortunately knew how to get to the site. Having arrived at the disaster in his own car, he initially had some difficulty in finding the incident co-ordinating officer and thereafter had more difficulty in identifying himself to the emergency authorities. Neither the police nor the ambulance service was particularly interested in the site senior medical officer, and he had great difficulty getting any messages through to the major accident officer. The sorting of casualties into urgent and non-urgent cases was not attempted, as the ambulance men were transferring them as quickly as possible to hospital, without performing any first aid.

\section{Discussion}

Most hospitals have a major accident procedure, and the outline plan of a hospital's relationships with the emergency services and other hospitals in the area is now well established (Fairley, 1969). After all the work we had put into our procedure we were naturally very despondent about the many weaknesses in our plan that had been brought to light, both in the internal organization of the hospital and in its relationships with outside bodies. It was salutary, on reviewing the extensive North American literature on the subject, to find that many of our failures were common to all disasters (Savage, 1970).

The exact words to be used by the police authority in alerting the hospital has been agreed on, and the hospital now receives a higher level of priority on the police action cards. It would appear trite to mention how vital it is that all hospital telephonists should know who the major accident officer is, and as his deputies we have nominated the duty medical registrar and the duty senior administrative nursing officer.

This exercise showed that the duties of our major accident officer are administrative, but for him to be able to give advice and to make decisions on many aspects of the emergency he should be a permanent member of the hospital's medical staff. Apart from the major accident officer and the site senior medical officer, we have worked on the assumption that for the initial build-up of medical staff we could rely on only the resident junior staff on duty being at the hospital for the first 30-60 minutes. Of course, during a working day there would be a large number of both senior and junior medical staff on the premises, but in the evenings and at weekends medical staff would have to called from their homes. All doctors report to the major accident officer in the control centre, where each is given an action card detailing his instructions, depending on whether the doctor is in the consultant/registrar or senior house officer/house-officer grade. By handing out the action cards in order the various treatment rooms and departments are staffed to a level of professional skill which corresponds to the type of patient who will be allocated to these areas.

The control centre should be sited conveniently near to the accident and emergency department, the main entrance of the hospital, and the wards, without being in the actual "front line." There should be enough telephones for communication with the hospital switchboard and other parts of the hospital, 
as well as adjacent subsidiary rooms with telephones. The key personnel in the control centre should be the major accident officer, the matron, and the hospital secretary, and we found it essential that they be together in the same room, rather than in separate rooms. To improve communications we have provided a direct line or intercom from the control centre to the accident and emergency department. We also advocate the provision of radiotelephones, so that the major accident officer and the site senior medical officer can be in continuous voice-to-voice contact with each other.

We think that it is important that the site senior medical officer should be a consultant, as only a doctor on the permanent staff of the hospital will have enough knowledge of local conditions to fulfil all the requirements of this responsible post. The two main functions of the site senior medical officer are to supervise the triage of casualties, so that the more severely injured are dealt with first, and to spread the load among the hospitals of the group. In carrying out the second function he should be guided not so much by the number of beds that could be made available at the hospital in an emergency as by the physical facilities and the level of medical staffing available to treat severely injured patients at the particular time of the accident.

One aspect of the exercise which helps to explain the almost complete collapse of the accident and emergency department was that casualties at the scene of the accident were mostly lying in the roadway, instead of being scattered over a large area. The firemen, having put out the fire in five minutes, helped the ambulance men to load the injured into the ambulances and, as no first aid was carried out by the ambulance service, casualties were transported to the hospital with extreme rapidity.

\section{New Arrangements}

The post of medical assessor is a new one, which we have found essential to create in the light of our experience. The senior doctor who was nominally in charge of the accident and emergency department during the exercise found that he soon lost control of the situation for three reasons. Firstly, we had not previously made any arrangements for cases to be assessed in the actual entrance of the department, and with the rapid admission of casualties the department was soon overwhelmed with patients and stretchers scattered everywhere. Secondly, the vital point was not made that the assessing doctor must only assess the casualties and not attempt to treat them. Thirdly, we had made no arrangements for him to have any form of clerical help.

We have now arranged for all casualties to enter the accident and emergency department through one door, where they are rapidly examined by the medical assessor. A nurse or clerk has a supply of consecutively numbered major accident casualty cards overstamped "Dead," "Immediate," "Urgent," and "Non-urgent." In the pocket of each card are placed the following, each appropriately numbered: two labels to which are attached long tapes, one blood cross-matching form, one pathology request form, and one $x$-ray request form. While the medical assessor examines the patient a nurse attaches the numbered labels to the patient's ankle and wrist. A second nurse records the patient's sex and approximate age on a check-list and, on the instructions of the assessor, rings the casualty card "Immediate," "Urgent," etc., as appropriate, and places it in a prominent position on the patient. No other information is recorded and the patient moves into the department. Nursing staff are now allocated to their posts by being handed action cards detailing their instructions. The object of the medical and nursing staff action cards is to staff the various resuscitation and treatment rooms to an appropriate level as rapidly as possible and, as the order in which each room is staffed is the same, the nurse in charge of the department is able to direct patients needing treatment to the appropriate room.

In peacetime conditions it is difficult to foresee a major accident situation in the area where a large concentration of skilled medical personnel would be required at the site. With many hospitals in close proximity a large and efficient ambulance service, and no major geographical hazards, apart from fields and woods, there should be very little delay in transporting casualties from the scene of the accident to nearby hospitals. This exercise confirmed our suspicions that in the early stages of a disaster we would find it difficult to provide sufficiently experienced and skilled doctors to be medical members of a team going to the site and still have enough doctors to attend the casualties when they arrive at the hospital. We have therefore recommended that the hospital should be prepared to send either a mobile medical team or a major accident unit.

The mobile medical team would be staffed and equipped mainly to help release trapped casualties, and it is for this reason that we have stipulated that the doctors be "senior," to the extent that they should be able to give a general anaesthetic and amputate a limb in difficult circumstances. Their equipment is packed in haversacks so that it can be easily carried to the patient. The major accident unit would be used only to support a hospital in another area or to set up a field hospital in the area of the incident.

The hospital switchboard worked well, but since the exercise we have amended the order in which calls are made. When the order is given to "carry out major accident instructions" the first call is made to all off-duty telephonists, since we found it difficult to maintain communications unless the switchboard was fully manned, and the early provision of relief telephonists is essential if efficiency and accuracy are to be maintained. As the accident and emergency department will be taking the full brunt of the casualties, it should be informed next. With the alerting of the matron and the hospital secretary, or their deputies, and the duty porter the key administrative personnel are informed. We then alert the senior members of the resident junior staff, the duty radiographer, and the pathology technician. Calls to the medical records officer and the duty house-officers complete the alerting of resident junior staff and ancillary staff needed to deal with the immediate problem of a major accident. Duty consultant staff of all specialties are then informed. Another action card lists administrative and ancillary staff to be called, and a third action card is used at the request of the major accident officer and involves calling in all the off-duty medical staff of the hospital. Action cards are also used by the portering staff. Each card tells the individual porter his duties, and by using the cards in order the level of staffing of all departments is known at any one time.

Though the police are anxious to have details of the injured as soon as possible, we found that attempts to obtain full documentation in the accident and emergency department interfered with clinical management, and where patients were being admitted there was no time for the usual admission procedure to be carried out while patients were en route to the ward. We recommend that no attempt be made to document patients in the accident and emergency department, apart from issuing numbered casualty cards to all patients. The medical assessor will know at any time how many casualties have entered the department, and the medical records officer and her staff will be able to obtain details from non-urgent patients in their treatment areas and from those admitted to the receiving ward.

\section{Conclusions}

A hospital's major accident procedure has to serve several purposes. It must designate a number of individuals to key positions in the hospital and must give them sufficient instructions so that they know what their duties are. These 
instructions, however, must not be too detailed as to prevent them from being read at the time of the emergency or to inhibit personal initiative. Other important members of the hospital staff also have vital tasks to perform, but it is equally important that their instructions should be explicit and detailed and that individual initiative, so far as the organizational side is concerned, should be discouraged. Other members of the staff-medical, nursing, and ancillary-must know who to report to in order to receive verbal or written instructions.

Of the many lessons we learnt, three stand out. Firstly, communications must be secure, both inside the hospital, with direct lines connecting vital centres, and outside, with a direct radio link between the major accident officer and the site senior medical officer. The hospital must also have exdirectory lines, so that outgoing calls can still be made if the switchboard is swamped with incoming calls. Secondly, written instructions in the form of action cards must be provided in key positions. We have installed major accident boxes containing copies of the major accident procedure, action cards, and other items of equipment in the control centre and accident and emergency department and at the main reception desk. Thirdly, hospital personnel must be made constantly aware of their duties in a major accident, by means of permanent display charts and by regular departmental discussions with the major accident officer.

\section{REFERENCES}

Fairley, J. (1969). British Medical fournal, 4, 551.

Savage, P. E. A. (1970). Disaster Planning-a review. Awaiting publication.
Britain has been a settled community for more than a thousand years. But in the seventeenth and eighteenth centuries there were still isolated areas in England that demanded from their sons qualities of sturdy independence similar to those that in later years pushed the American frontier westwards and developed the Australian Outback. One such area in this country was the Yorkshire dales, a group of rugged but beautiful glacial valleys cut in the Pennine limestone in the north-west corner of Yorkshire.

Between 1697 and 1780 these isolated valleys produced a remarkably talented group of doctors, all of whom were characterized by their originality, and many of whom are remembered today for their contributions to the advancement of medical knowledge. They included John Fothergill of Ravdale (Hingston Fox, 1919; Corner and Singer, 1954; Booth, 1957); William Hillary of Wensleydale, the first man to describe tronical sprue clearly and George Washington's doctor in Barbados (Booth, 1963); John Haygarth, who pioneered isolation techniques in the prevention and treatment of infectious fevers (Weaver, 1930); Anthony Askew, one of the owners of John Radcliffe's famous gold-headed cane; Anthony Fothergill of Sedbergh; George Birkbeck, after whom Birkbeck College is named; and Robert Willan, the famous dermatologist (Booth, 1968). To these must be added John Coakley Lettsom, who served his apprenticeship to a Quaker apothecary, Abraham Suttcliffe, at Settle in Ribblesdale (Johnston Abraham, 1933). As with pioneers in other continents, many of these men were radicals and nonconformists, a reflection of the individualism of those rugged but lovely valleys. All but one lived for the early and formative part of their years in these Yorkshire dales, and most were educated at the famous grammar school at Sedbergh. But none stayed in the land of their birth, their ambitions leading their medical careers to cities such as Rinon, Bath, Northampton, Darlington, Edinburgh, London, and Leiden, and in two instances to places as far afield as Pennsvlvania and the West Indies.

This paper describes another, humbler son of one of these

\footnotetext{
* Paper read to the Osler club on 11 June, 1970.

+ Professor of Medicine, Royal Postgraduate Medical School, London W.12.
}

Yorkshire valleys, a man who had no formal education and who was virtually self-taught. Yet he became a doctor, knew and taught some of his distinguished compatriots; but he worked for most of his long life as a country practitioner in the valley of his birth. He was also a remarkable mathematical genius who developed a national reputation, and this brought to him as pupils at his modest home at Sedbergh 12 men who were to become senior wranglers at the University of Cambridge (Clark and Hughes, 1890).

\section{Early Years}

John Dawson was born at Raygill Farm in Garsdale in 1734. His father, William Dawson, was a "statesman" earning at that time not more than $£ 10$ or $£ 12$ in a year. Dawson's birthplace is little altered by the passage of nearly 250 years, and the valley of Garsdale, never penetrated by railway or bus route, scarcely visited by tourists even today, is serene and untroubled by the passing centuries. Inside the house the present occupants preserve a carved cupboard door on which can be read the initials J.D. 1667, an earlier member of the Dawson family.

Until he was over 20 years of age John Dawson worked as a shepherd on the hills. High on the moor above his home there is a stone called Dawson's Rock where, according to local tradition, young Dawson sat and worked out a system of conic sections entirely for himself. His family's limited resources made formal education unavailable to him, and according to one account Dawson educated himself by begging or borrowing books and doing a little teaching. As early as 1756, however, when he was 22 years old, his reputation as a rural intellect began to be known locally, and in the summer of that year three young men about to enter the University of Cambridge went to read with him. The first was John Havgarth, born in Garsdale at nearby Swarthgill (Elliott, 1913). Haygarth in that year was 16 years old and was later to become internationally famous for his work on the epidemiology of infectious disease. The second was a young man called Sedgwick, who became vicar of Dent and the father of Adam Sedgwick, professor of geology at the Univer- 